detained in the goalbox for $20 \mathrm{sec}$, with the sliding delay door closed. The intertrial interval was approximately $30 \mathrm{sec}$.

\section{RESULTS}

Acquisition

Analyses of variance were performed on start speeds $(\mathrm{ft} / \mathrm{sec})$ and running speeds ( $\mathrm{ft} / \mathrm{sec}$ ) over acquisition in blocks of eight trials. The analysis of variance design incorporated reward magnitude on I trials, $D$ length, blocks and replications. ${ }^{2}$ The results of these analyses indicated that: (1) neither the reward magnitude on I trials nor the D length had a statistically significant effect on start or running speeds $(\mathrm{F}<1)$; (2) the blocks effect was significant for both start speeds and running speeds $(\mathrm{F}=160.42$ and 274.76 , $\mathrm{df}=7 / 385$, respectively, $\mathrm{p}<.01$ ); and (3) the Reward Magnitude on I Trials by $D$ Length interaction was statistically reliable for start speeds $(F=7.06$, $\mathrm{df}=1 / 55, \mathrm{p}<.05)$ but not for running speeds $(F=3.83, d f=1 / 55, p>.05)$. To evaluate the interaction, separate $t$ tests were performed and indicated that Group $8 D(1)$ ran significantly faster $(\mathrm{t}=4.85, \quad \mathrm{df}=30, \mathrm{p}<.01)$ than Group 8D(1-3), and that Group 2D(1-3) ran substantially faster $(t=3.00, d f=29$, $\mathrm{p}<.01)$ than Group 2D(1).

Extinction

Analysis of variance was performed on start speeds $(\mathrm{ft} / \mathrm{sec})$ over blocks of eight trials. The results of these analyses indicated that magnitude of reward on I trials was not a relevant factor $(F=1.80$, $\mathrm{df}=1 / 55, \mathrm{p}>.05)$. The $\mathrm{D}$-length variable also failed to affect start speeds during extinction $(F<1)$. The blocks effect was significant beyond the .01 level $(F=72.37$, $\mathrm{df}=3 / 165$ ), and the Reward Magnitude on I Trials by $D$ Length interaction failed to be statistically significant $(\mathrm{F}<1)$.

Fig. 1 presents the mean running speeds as a function of trial blocks. As may be seen in Fig. 1, the groups receiving the longer $D$ length were most resistant to extinction. Analyses of variance performed on running speeds ( $\mathrm{ft} / \mathrm{sec}$ ) over blocks of eight trials revealed that the longer $D$ length produced a significantly greater resistance to extinction $(F=5.73$, $\mathrm{df}=1 / 55, \quad \mathrm{p}<.05)$. The Reward Magnitude on I Trials by D Length interaction failed to achieve statistical reliability $(F<1)$. The blocks effect was statistically reliable $(F=145.15$, $\mathrm{df}=3 / 165, \mathrm{p}<.01$ ) as well as the Blocks by $D$ Length interaction $(F=4.93$, $\mathrm{df}=3 / 165, \mathrm{p}<.01$ ).

\section{DISCUSSION}

The extinction data lend support to the findings of Capaldi (1967a) in that $D$ length was a significant determiner of resistance to extinction. A most critical finding of the study, however, was that the increased reward magnitude on I trials was not sufficient to reflect differences in extinction. Refutation of Capaldi, Godbout \& Downs' (1968) results cannot be claimed because of the difference in levels of reward magnitude. While the present study used 2 and 8 pellets, Capaldi et al used 2 and 24 pellets. The failure of Group 8D(1-3) to run faster than Group 2D(1-3) during extinction might, therefore, be explained on the basis that, with irregular schedules of partial delay, conditioning of $S^{D}$ persisting from preceding $\mathrm{D}$ trials necessitates relatively large reward magnitude on I trials.

\section{REFERENCES}

CAPALDI, E. J. Sequential versus nonsequential variables in partial delay of reward. Journal of Experimental Psychology, 1967a, 74, 161-166. CAPALDI, E. J. A sequential hypothesis of instrumental leaming. In K. W. Spence and $J$. T. Spence (Eds.), The psychology of learning and motivation: Advances in research and theory. Vol. 1. New York: Academic Press, 1967b. Pp. 67-156.

CAPALDI, E. J. GODBOUT; R. C., \& DOWNS, B. Joint effects of magnitude of immediate reward and magnitude of delayed reward on acquisition and extinction. Psychonomic Science, 1968, 13, 277-278. NOTES

1. The authors wish to thank Neil H. Cohn for his assistance.

2. The replications factor was significant throughout both the acquisition and extinction data. Since the interactions of replication with reward magnitude on I trials and also with $D$ length was not significant, the replications data was not reported in the present study.

\title{
Training schedules and the E-effect on the acquisition of a two-turn task in a temporal circular maze
}

HEATHER MOHAY $Y^{1}$ and CHIA-SHONG CHEN, Monash University, Melbourne, Australia

Eighteen male and 18 female hooded rats were trained to perform a two-turm task in a temporal circular maze to evaluate the effects of different training schedules on acquisition rate. Ss were randomly allocated to the two Es (HM and CSC), and also to one of three training schedules: (1) $4 \times(2 G 2 F)$, i.e., four repetitions of two guided trials followed by two free trials; (2) $2 \times(4 G 4 F)$; (3) $1 \times(8 G 8 F)$. At the termination of the experiment, a mareked, and quite unexpected, E-effect was noted, HM's Ss learning in significantly fewer trials than CSC's Ss. An attempt was made to trace the mediating factors; the only consistent differences that could be found existed in the manner of handling the $S s$ in the initial stages, i.e., before pretraining. Significant differences were also found between the different training schedules used, learning occurring more slowly on the $1 \times(8 G 8 F)$ schedule than on either of the other two.

This experiment was designed to study a hypothesis suggested by Chen (1967): the pattern of guided and free trials is of greater importance than the overall number of these trials in the acquisition, by rats, of a two-turn task in a temporal circular maze. At the conclusion of this experiment, it was noted that there existed a very strong $E$ effect on the rate of acquisition. A similar E-effect phenomenon has been reported by Rosenthal et al $(1963,1964)$, in both discrimination learning and operant learning situations, and by Brogden (1960), in an avoidance learning situation.

\section{SUBJECTS}

Eighteen male and 18 female experimentally naive hooded rats from the Monash University colony, aged 60-70 days at the commencement of the experiment, were housed individually, with ad lib water, and maintained at approximately $80 \%$ estimated growth weight throughout the experiment. Nine male and nine female Ss were allocated randomly to each of the two Es, and within these two subgroups Ss were randomly allocated to one of three training schedules after the completion of the preliminary training (see Procedure below).

\section{APPARATUS}

Figure 1 shows the ground plan of the maze, a detailed description of which is available elsewhere (Chen, 1967). In this maze situation, $S$ was required to make two complete circuits of the circular runway, in the same direction, before reentering the stem; if more or less than the required number of circuits was made the trial was counted as an error and the reward (one 50-mg pellet), which was given at the end of every correct trial, was withheld. A trial was defined as at least one complete circuit of the circular runway 


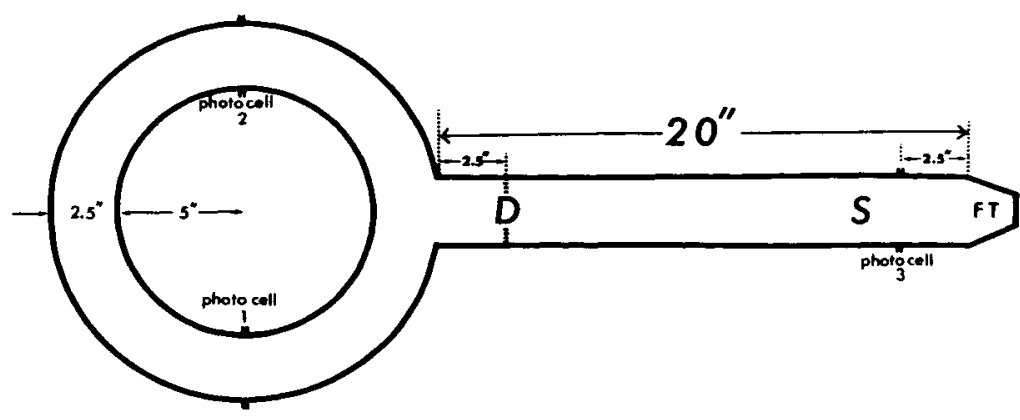

before reentering the stem, and was Photocell 3. The stem therefore acted as both the startbox and the goalbox on any one trial, and thus, once $S$ was introduced into the maze, the total number of trials could be run without intertrial handling.

\section{PROCEDURE}

During the 1st week, each $S$ was weighed daily and handled and allowed to explore for approximately $1 \mathrm{~min}$ each day. Food was available for $1 \mathrm{~h}$ after handling, and $\mathrm{Ss}$ were reduced to approximately $80 \%$ estimated growth weight. Throughout the experimental training, Ss were fed a $1 / 2 \mathrm{~h}$ after training and were maintained at this weight.

\section{Preliminary Training}

On Day 1, 10 pellets were placed in the food tray (FT) with Door D closed, and S was placed in the stem and allowed to remain there until the 10 pellets had been eaten or $10 \mathrm{~min}$ elapsed, whichever came first. From Day 2 to Day 4, five pellets were placed in the FT, D was opened, and $S$ was allowed to eat the pellets and to explore the maze. Each time $S$ made a complete trial, i.e., at least one complete circuit of the circular runway, a pellet was dropped into FT manually. $\mathrm{S}$ was allowed to remain in the maze for 10 min or until a to Day $12, S$ received five trials a day, with pellets being dispensed through a pellet dispenser at the end of each trial. Two or three extra trials were given to Ss that were timid on the last 3 days. Experimental training began on the following day. Experimental Training

At the completion of the preliminary trial.

\section{RESULTS AND DISCUSSION} counted complete only when $S$ reached total of five trials were made. From Day 5

training, Ss were assigned randomly to one of the following three training schedules: (1) $4 \times(2 G 2 F)$, i.e., four repetitions of two guided trials followed by two free trials, (2) $2 \times(4 G 4 F)$, and (3) $1 \times(8 G 8 F)$; thus all Ss received a total of eight guided and eight free trials each day. On guided trials, Door D was closed when $S$ entered the circular section of the runway and opened again when $S$ had almost completed the second circuit, thus forcing a correct trial. On free trials, D was left open so that $S$ could make either a correct or an erroneous response. When $S$ made two or more consecutive correct responses, guidance was withheld until two consecutive errors were made. Five consecutive correct trials was set as the criterion for learning, and guidance was permanently withheld when the criterion was attained. $S$ received 10 more free trials immediately following the 5 th criterion

The data indicate that there was no difference between the male and the female Ss with regard to the rate of learning; therefore, their results have been combined. Table 1 summarizes the results obtained by the two Es. It will be noted in the table that a striking but unexpected $E$ effect exists. By the time the experiment was discontinued, 14 of the $18 \mathrm{Ss}$ trained by $\mathrm{HM}$ reached the criterion, while only 5 of the $18 \mathrm{Ss}$ trained by CSC did so. The median total trials to criterion for the HM group was 394.5 and the median of the CSC group was greater than 610 , which was the largest number of trials given by the end of the experiment. The medians

Table 1

Median Total Trials to Criterion for Experimental Groups Trained by Two Es Under Three Training Schedules

\begin{tabular}{|c|c|c|c|c|c|c|c|c|c|}
\hline \multirow[b]{2}{*}{$\underline{E}$} & \multicolumn{3}{|c|}{$4 \times(2 G 2 F)$} & \multicolumn{3}{|c|}{$2 \times(4 G 4 F)$} & \multirow[b]{2}{*}{$\begin{array}{c}\text { Number } \\
\text { of Ss }\end{array}$} & \multicolumn{2}{|c|}{$1 \times(8 G 8 F)$} \\
\hline & $\begin{array}{c}\text { Number } \\
\text { of Ss }\end{array}$ & Median & Range & $\begin{array}{c}\text { Number } \\
\text { of Ss }\end{array}$ & Median & Range & & Median & Range \\
\hline HM & 6 & 392 & $212-609$ & 6 & 340.5 & $187-504$ & 2 & $\begin{array}{c}\text { larger } \\
\text { than } \\
610\end{array}$ & $386-a$ \\
\hline $\csc$ & 2 & $\begin{array}{c}\text { larger } \\
\text { than } \\
610 \\
\end{array}$ & $423-a$ & 3 & $\begin{array}{c}\text { larger } \\
\text { than } \\
610\end{array}$ & $505-a$ & 0 & $\begin{array}{c}\text { larger } \\
\text { than } \\
610 \\
\end{array}$ & $\mathrm{a}$ \\
\hline
\end{tabular}

a-exact data not available
Fig. 1. Plan view of maze.

were found to differ significantly by a median test $\left(\chi^{2}=5.44\right.$, df $\left.=1, p<0.02\right)$.

Efforts were made to trace down the possible mediating factors for this unexpected result. "Clever Hans type cues" were first suspected when the existence of E effect became evident. But this possibility was excluded by the facts that changing the position of $E$ in relation to the maze on different days and each $E$ running the other E's Ss after they had learned or when they were just about to learn did not affect the performance. Training methods were late $i$ analyzed carefully and the only consistent differences that could be determined was in the way Ss were handled, especially during the week prior to the commencement of pretraining. During this period, HM tended to handle her Ss a great deal more than CSC, who generally placed his Ss on a bench to explore and then picked them up every $20-30 \mathrm{sec}$. Whether or not this is the cause for the $E$ effect observed remains to be determined, but it is in line with Rosenthal's suggestion that the Es' attitudes to the animals and the way in which they handle their Ss are important mediating factors in the $E$ effect. It must, however, be emphasized that in this experiment both Es set out with the same expectation, whereas the expectations of Rosenthal's Es differed.

As to the effect of training schedules on the rate of acquisition, a Kurskal-Wallis one-way analysis of variance by ranks shows that the overall effect among three groups trained by $\mathrm{HM}$ was significant at the 0.1 level $(H=5.16, \quad d f=2, p<0.1)$. Furthermore, a median test on the combined results of the two Es shows that the groups differ significantly at the 0.02 level $\left(\chi^{2}=8.67, \mathrm{df}=2, \mathrm{p}<0.02\right)$. The results lend support to the hypothesis that it is the way in which guided and free trials are combined, rather than the total number of such trials, that is the important factor in determining the rate of acquisition. REFERENCES

BROGDEN, W. J. The experimenter as a factor in animal conditioning. Psychological Reports, $1962,11,239-242$.

CHEN, C. S. Training schedule in a two-turn task in a temporal circular maze. Psychonomic Science, 1967, 9, 273-274.

ROSENTHAL, R., \& FODE, K. L. The effect of experimenter bias on the performance of the albino rat. Behavioral Science, 1963, 8, 183-189.

ROSENTHAL, R., \& LAWSON, R. A longitudinal study of the effects of experimenter bias on the operant learning of laboratory rats. Joumal of Psychiatric Research, 1964, 2, 61-72. NOTE

1. Now at Tennessee School for the Deaf, Knoxville, Tenn. 